\title{
Optimization of oil and pectin extraction from orange (Citrus sinensis) peels: a response surface approach
}

\author{
Olugbenga Abiola Fakayode* and Kingsley Emmanuel Abobi
}

\begin{abstract}
The effects of processing parameters on essential oil and pectin extractions from orange peels were investigated using response surface approach; $2 \times 5$ and $3 \times 5$ central composite rotatable designs were adopted for the essential oil and pectin extractions, respectively. Extraction temperatures $\left(80-100^{\circ} \mathrm{C}\right)$ and extraction times $(120-240 \mathrm{~min})$ were chosen for essential oil extraction, while extraction temperatures (80-100 min), extraction times (60-120 min), and extraction $\mathrm{pH}$ (1.0-3.0) were chosen for pectin extraction. Essential oil yield ranged from 0.57-3.24\%, while pectin yield ranged from $12.93-29.05 \%$. The predicted optimum value for essential oil yield was $3.38 \%$ at extraction temperature of $95.23^{\circ} \mathrm{C}$ and extraction time of $231.30 \mathrm{~min}$, while the predicted optimum value for pectin yield was $30.00 \%$ at extraction temperature of $93.07^{\circ} \mathrm{C}$, extraction time of $117.00 \mathrm{~min}$, and extraction pH of 1.60. Deviations between experimental and predicted values were low and statistically insignificant. All processing factors have significant effects on both extractions. The physicochemical properties of the essential oil and pectin extracted at the optimum conditions fell within tolerable and acceptable range.
\end{abstract}

Keywords: Essential oil (EO), Pectin, Extraction temperature, Extraction time, Extraction pH, Optimization, Response surface methodology (RSM), Physicochemical properties

\section{Introduction}

Citrus represents one of the major fruits in the world. The fruits belong to six genera (Fortunella, Eremocitrus, Clymendia, Poncirus, Microcitrus, and Citrus), but the major commercial fruits belong to genus Citrus which consists of several important fruits, viz. oranges, lemons, limes, grapefruit, mandarins, and pomeloes (Chanthaphon et al. 2008). Orange, specifically, the sweet orange (Citrus sinensis) is the most commonly grown tree fruit in the world (Pandharipande and Makode 2012). Orange trees are cultivated extensively in tropical and subtropical climates due to the sweet fruit obtained. The fruits are peeled or cut (for bitter rind avoidance) and eaten skinned; or processed to orange juice by extraction. Orange fruits are majorly utilized by juice processing industries, with the peels categorized as wastes. Even at homes, orange peels are discarded inside waste container because people love the orange pulp for its juicy pulp and

\footnotetext{
* Correspondence: gbengafakayode@uniuyo.edu.ng

Department of Agricultural and Food Engineering, University of Uyo, Uyo, Akwa Ibom State, Nigeria
}

discard the peel as it does not taste as great as the pulp. In lieu of this, since the yield of orange juice is half of the fruit weight (Hashmi et al. 2012), a very large amount of orange by-product wastes are generated annually. Fernández-Lopes et al. (2004) reported that the by-products from orange juice processing pose a serious problem to the industry, given their limited applications and low added value. However, Nogueira et al. (2000) observed that the orange agro-industry is amongst the sectors producing large amounts of waste with possibilities for use. This recovery is absolutely connected to sustainable development and the marketability of these by-products. As there is always an increased concern about bringing useful products from waste, orange fruit wastes are no exceptions. Amongst the biologically active compounds (BAC) in these by-products are essential oils (EOs) and pectin.

Essential oils are mixtures of many compounds consisting mainly of isoprenoids, monoterpenes, and sesquiterpenes (Marin et al. 2007). They are a group of volatile aromatic compounds produced by several plant species. These BAC are responsible for the scents of many 
aromatic plants (Rossi et al. 2011; Yu et al. 2011) and can be used for pharmaceuticals, food flavor additives, and natural antimicrobials amongst others (Bakkali et al. 2008). Essential oils are utilized in the manufacture of food and medicines as flavoring agents, cosmetics, and domestic household products (Braddock et al. 1986). They also exhibit antibacterial, antifungal, and insecticidal properties (Burt 2004; Thormar 2011; and Zoubiri and Baaliouamer 2014). They are produced from orange peel extraction using several extraction methods which include steam or hydro-distillation, water, steam and organic solvent extraction, cold pressing, and supercritical $\mathrm{CO}_{2}$ (Palazzolo et al. 2013). Essential oils from orange peels are very complex matrices which consist of many compounds of various chemical classes which are majorly separated into two parts, viz. the volatile part which constitutes between 85 and $99 \%$ and the non-volatile part which constitutes between 1 and 15\% (Palazzolo et al. 2013). The oil content of citrus peels range between 0.5 and $5.0 \%(w / v)$ as reported by Palazzolo et al. (2013). They are complex natural mixtures of lipophilic substances constituting about 20-60 components at different concentrations and consist of two or three major components, namely limonene, pcymene, and ocimene at fairly high concentrations (20-70\%) compared to other components which are present in trace amounts (Palazzolo et al. 2013). Several factors affect the quality, quantity, and composition of orange peel essential oil which include the nature of the fruit, provenance, genotype, soil type, climate, plant organ, age, vegetative cycle, and the extraction process (Dugo et al. 2000 and Palazzolo et al. 2013).

Pectin is produced commercially in the form of white to light brown powder mainly extracted from orange fruits. They can be produced from orange peels using several methods which include microwave, ultrasound, high pressure, subcritical water, enzyme utilization, electromagnetic induction heating, and combination of chelators like citric acid in the conventional process (Putnik et al. 2017). Pectin is a complex mixture of polysaccharides which occurs in the primary cell walls of terrestrial plants. It is composed of a linear backbone of $\alpha$ (1-4)-D-galacturonic acid residues which is partially esterified with methanol, with periodic interruptions to L-rhamose residues that make the backbone irregular and with some other neutral sugars present as side chains (Garna et al. 2004). Pectin consists of all the esterified polyalacturonic acids at various levels of neutralization (Pandharipande and Makode 2012). Large structural diversity is prevalent amongst pectin, chiefly because of the different plant origins and the extraction process being utilized. At present, commercial pectins are almost exclusively gotten from citrus peel, a by-product of juice manufacturing unit. The amount of pectin contained in orange peels is estimated by experiments. According to Rouse and Crandall (1976), May (1990), and Khan et al. (2015), dried citrus peel contains about $30 \%$ pectin (on dry basis). During pectin extraction from orange peels, several factors affect the process which include the $\mathrm{pH}$, temperature, solvent used for extraction, time of extraction, agitation rate, and liquid solid ratio (LSR) amongst others.

Several works have been done on essential oil and pectin extractions from orange peels, though the effects of processing factors on the extractions were not considered in some. Ezejiofor et al. (2011) worked on essential oil extraction from orange peels. Also, Hashmi et al. (2012) studied essential oil and pectin extraction from sweet orange. Nonetheless, the reports did not study the influence of processing factors on the oil and pectin yields. The effects of one of the process parameters on pectin yield during extraction from orange peels have been studied by several researchers. Pandharipande and Makode (2012) worked on the separation of oil and pectin from orange peel and studied the effect of $\mathrm{pH}$ on the pectin yield. Njoku and Evbuomwan (2014) considered the effect of extraction time on oil extracted from orange, lemon, and lime peels. Yadav et al. (2017) also studied the effects of $\mathrm{pH}$ on pectin yield extraction from sweet lime peels. In the above studies, other processing factors were not considered. According to Fan et al. (2011), the traditional one-factor-at-a-time approach is time-consuming and is almost impossible to achieve the true optimal conditions; therefore, it seems unrealistic to optimize the essential oil and pectin extraction processes using that approach. Some researchers studied the effects of more processing factors on pectin yield during extraction from orange peels; howbeit, the processing parameters were not optimized. Dehankar et al. (2015) studied the removal of essential oil and extraction of pectin. For the latter, the $\mathrm{pH}$, process period, and solvent used were considered but not optimized. El-Nawawi and Shehata (1987) and Rehmann et al. (2004) investigated the effects of temperature, $\mathrm{pH}$, and duration on pectin extraction from orange and mango peels, respectively. However, the process was not optimized. Nevertheless, there have been reports on the optimization of processing factors on pectin extraction from other fruit peels. Kliemann et al. (2009) optimized the effects of temperature, $\mathrm{pH}$, and extraction time on pectin acid extraction from passion fruit peel. Tang et al. (2011) optimized the effects of $\mathrm{pH}$, extraction time, and ethanol ratio on pectin acid extraction from dragon fruit peel.

The current annual world production of oranges has been estimated to be 49.3 million tons (USDA 2018). Nigeria is ranked ninth in the world amongst the leading citrus producing countries and first in Africa, producing 3.33 million tons of citrus fruits (The Daily Records 2018). Despite this high rank, the country's local 
production of essential oil and pectin is very low, as nearly $100 \%$ of the essential oils and pectin utilized by the various industries are imported. This is due to lack of appropriate and adequate data. This study therefore employs response surface methodology (RSM) to optimize the oil and pectin extraction process parameters. Development of mathematical models would be useful in predicting the responses during the essential oil and pectin extraction processes at different processing conditions, while the characterization of the essential oil and pectin at the optimum processing conditions will provide a true reflection of the quality, suitability, and potential of the extracted essential oil and pectin.

\section{Methods}

\section{Sample preparation}

Fresh oranges were purchased from the market. They were peeled, and the peels were removed, chopped into smaller pieces, and dried for 1-2 h. The dried peels were ground to give consistent and fine particles (this was essential to avoid clumping during solvent extraction) and stored at ambient temperature for further use.

\section{Experimental design}

The effects of extraction temperature and extraction time on essential oil yield from orange peels were investigated, while the effects of extraction temperature, extraction time, and extraction $\mathrm{pH}$ on pectin yield from orange peels were investigated. The experimental designs adopted were $2 \times 5$ and $3 \times 5$ factorial central composite rotatable design (CCRD) of response surface methodology for essential oil and pectin extractions, respectively. Central composite rotatable design consists of three types of design points, viz. factorial points $\left(n_{f}\right)$, axial points $\left(n_{a}\right)$, and central points $\left(n_{c}\right)$. The total number of treatment combinations is $n=2^{k}\left(n_{f}\right)+$ $2 k\left(n_{a}\right)+k\left(n_{c}\right)$ where $k$ is the number of independent variables and $n$ is the number of repetition of experiments at the center point. The total number of design points is thus $N=2^{k}+2 k+n_{o}$ (Fakayode and Ajav 2016). For essential oil extraction, 13 experiments were generated consisting of $2^{2}$ factorial CCD, with 4 axial points $(\alpha=2)$ and 5 replications at the center points, while for pectin extraction, 20 experiments were generated consisting of $2^{3}$ factorial CCD, with 6 axial points $(\alpha=2)$ and 6 replications at the center points. The various levels for each independent variable were selected based on preliminary experiments, observations, and previous reports by other researchers. For oil extraction, extraction temperatures $\left(80,85,90,95\right.$, and $\left.100{ }^{\circ} \mathrm{C}\right)$ and extraction times $(120,150,180,210$, and $240 \mathrm{~min})$ were chosen, while for pectin extraction, extraction temperatures $\left(80,85,90,95\right.$, and $\left.100{ }^{\circ} \mathrm{C}\right)$, extraction times $(60,75,90$, 105 , and $120 \mathrm{~min})$ and $\mathrm{pH}(1,1.5,2,2.5$, and 3$)$ were selected. The dependent factors considered in this study were considered as the most important factors affecting oil and pectin yield (Gama et al. 2015; Khan et al. 2015).

\section{Essential oil extraction}

Essential oil extraction from orange peels was done using the Soxhlet method. The orange peels were pureed using a blender. A round bottom flask was washed, oven dried, and cooled in a desiccator. A dried mass of $5 \mathrm{~g}$ of the puree was weighed using a filter paper, and the weight recorded as $W_{s}$. The weighed sample was wrapped in the filter, tied using a thread, and dropped in the Soxhlet extractor. N-hexane was added until it siphoned once, and more hexane was added until the barrel of the extractor was half full. The condenser was checked making sure that its joints were tight, and the cooling water was circulating (the water helps to cool the extractor which is necessary to prevent heat from heating up the Soxhlet extractor, thereby resulting in equipment damage). The heating mantle was adjusted to five different temperatures $\left(80,85,90,95\right.$, and $\left.100{ }^{\circ} \mathrm{C}\right)$ and left to boil gently in the round bottom flask for different durations (120, 150, 180, 210, and $240 \mathrm{~min})$. After this period, the n-hexane would have completely siphoned up to the Soxhlet extractor. The setup was dismantled, and the n-hexane recovered. A beaker was washed, oven dried, weighed, and the weight recorded as $W_{e}$. The miscella (oil + hexane) in the round bottom flask was transferred into the beaker and placed inside the steam bath for $4 \mathrm{~h}$ to completely evaporate the $\mathrm{n}$-hexane. After the n-hexane was completely evaporated, the beaker containing the sample was collected and the weight recorded as $W_{f}$. The percentage essential oil yield was calculated using Eq. (1):

$$
\mathrm{EOY}=\frac{\left(W_{f}-W_{e}\right)}{W_{s}} \times 100
$$

EOY = essential oil yield (\%), $W_{\mathrm{s}}=$ weight of sample $(\mathrm{g})$, $W_{\mathrm{e}}=$ weight of empty flask $(\mathrm{g})$, and $W_{\mathrm{f}}=$ weight of flask and extracted oil (g)

\section{Pectin extraction}

Pectin extraction from orange peels was done in two stages. Oil was first extracted from the orange peel samples after which pectin was isolated with acid hydrolysis technique as suggested by Pandharipande and Makode (2012). The inner part of the peels (albedo) contains the pectin, while the outer part (flavedo) contains d-limonene oil. Simple distillation was employed for essential oil removal from the orange peels. Twenty-five grams of dried orange peels was weighed into a steel container and blended in $1000 \mathrm{ml}$ distilled water. The homogenate was transferred to a $1500 \mathrm{ml}$ beaker, and the $\mathrm{pH}$ of the mixture was adjusted by adding 
hydrochloric acid drop wisely to get the desired $\mathrm{pH}$ values $(1,1.5,2,2.5$, and 3$)$. The mixture was heated at different temperatures $\left(80,85,90,95\right.$, and $\left.100{ }^{\circ} \mathrm{C}\right)$ and intermittently stirred. The $\mathrm{pH}$ was adjusted every 15 min, and lost water replaced. Mixture was rapidly cooled to $40{ }^{\circ} \mathrm{C}$ in an ice bath and filtered using Whatman filter paper under vacuum. The filtrate was transferred to another steel container and coagulated using equal amount of $95 \%$ ethanol and left for different durations $(60,75,90,105$, and $120 \mathrm{~min})$ to allow the pectin float on the surface. The gelatinous pectin flocculants were cleared off using a spatula, and the weight was determined. The gelatinous pectin flocculants were filtered through cheese cloth and washed with $95 \%$ ethanol to remove the remaining impurities; thereafter, it was washed with acetone drop wise and filtered again through cheese cloth. It was then dried at $60-70{ }^{\circ} \mathrm{C}$ overnight in an air-forced oven. The percentage of dried pectin yield was calculated using Eq. (2):

$$
\mathrm{DPY}=\frac{W_{\mathrm{d}}}{W_{\mathrm{p}}} \times 100
$$

DPY = dried pectin yield (\%), $W_{\mathrm{d}}=$ weight of dried pectin obtained $(\mathrm{g})$, and $W_{\mathrm{p}}=$ initial weight of orange peel powder used for extraction (g).

\section{Characterization of orange peel essential oil}

The essential oil extracted from orange peels at the optimum processing conditions (the highest yield) was characterized by determining the physicochemical properties.

Determination of specific gravity of orange peel essential oil All experiments were carried out in triplicates, and average values taken. This was determined using the procedure described by Adepoju and Eyibio (2016). A specific gravity bottle was washed, dried, and filled with water. It was weighed and recorded as $W_{\mathrm{w}}$. The bottle was emptied and properly dried after which it was filled with the oil. It was also weighed and recorded as $W_{\mathrm{o}}$. The specific gravity was calculated using Eq. (3):

$$
\mathrm{SG}=\frac{W_{\mathrm{w}}}{W_{\mathrm{b}}} \times 100
$$

$\mathrm{SG}=$ specific gravity of orange peel essential oil, $W_{\mathrm{w}}=$ weight of specific gravity bottle filled with water $(\mathrm{g})$, and $W_{\mathrm{b}}=$ weight of specific gravity bottle filled with oil (g)

Determination of free fatty acid of orange peel essential oil This was determined as reported by Fakayode et al. (2016). Ten grams of the oil sample was accurately weighed into a 250-ml stopper flask. In a second flask, $50-\mathrm{ml}$ of ethanol was heated to the boiling point, and while still over $70{ }^{\circ} \mathrm{C}$, it was neutralized with $0.1 \mathrm{M}$ potassium hydroxide using phenolphthalein indicator. The neutralized ethanol was poured in the first flask containing the oil, and the content of the flask mixed. They were boiled, and while still hot, titrated with $0.1 \mathrm{M}$ potassium hydroxide, shaking vigorously during the titration. The end point of the titration was reached when the addition of a single drop of $0.1 \mathrm{M}$ potassium hydroxide produced a slight, but definite color change persisting for at least $15 \mathrm{~s}$. The FFA was then calculated using Eq. (4):

$$
\mathrm{FFA}=\frac{28.2 \times V \times N}{W_{\mathrm{o}}}
$$

$\mathrm{FFA}=$ free fatty acid $(\mathrm{mg} \mathrm{KOH} / \mathrm{g}), V=$ volume of $0.1 \mathrm{M}$ potassium hydroxide used $(\mathrm{ml}), N=$ normality of the ethanolic potassium hydroxide $(0.1 \mathrm{M})$, and $W_{o}=$ weight of oil (g)

\section{Determination of acid value of orange peel essential oil} This was determined using the procedure described by Njoku and Evbuomwan (2014). Twenty-five milliliters of diethyl ether and $25 \mathrm{ml}$ of ethanol were mixed in a $250 \mathrm{ml}$ beaker. The resulting mixture was added to $5 \mathrm{~g}$ of the oil in a $250 \mathrm{ml}$ conical flask. Few drops of phenolphthalein were added to the mixture, and the mixture was titrated with $0.1 \mathrm{M}$ potassium hydroxide and consistently shaken until a dark pink color was observed. The volume of the $0.1 \mathrm{M}$ potassium hydroxide was noted. The acid value was calculated using Eq. (5):

$$
\mathrm{AV}=\frac{56.1 \times V \times N}{W_{\mathrm{o}}}
$$

$\mathrm{AV}=$ acid value of orange peel essential oil (mg $\mathrm{KOH} / \mathrm{g})$

\section{Determination of saponification value of orange peel essential oil}

This was determined as reported by Ezejiofor et al. (2011). Two grams of the oil was weighed into a $200 \mathrm{ml}$ conical flask, and $50 \mathrm{ml}$ of $0.5 \mathrm{M}$ alcoholic potassium hydroxide was added. This was refluxed for $1 \mathrm{~h}$, followed by the addition of two drops of phenolphthalene indicator and was titrated with $0.5 \mathrm{M}$ hydrochloric acid until the pink color disappears. A blank titration was equally performed. The saponification value was calculated using Eq. (6):

$$
\mathrm{SV}=\frac{28.05 \times(B-S)}{W_{\mathrm{o}}}
$$

$\mathrm{SV}=$ saponification value of orange peel essential oil (mg $\mathrm{KOH} / \mathrm{g}), B=$ blank titration value $(\mathrm{ml})$, and $S=$ sample titration value $(\mathrm{ml})$ 
Determination of iodine value of orange peel essential oil This was determined as reported by Takeoka et al. (1997). Three hundred milliliters of the oil was weighed and dissolved in $15 \mathrm{ml}$ of cyclohexane. Twenty-five milliliters of Wijs solution was added, and the reaction was carried out in the dark for $1 \mathrm{~h}$. The reaction was stopped by adding sodium iodide solution. The remaining iodine was titrated using $0.1 \mathrm{M}$ sodium thiosulfate solution. The iodine value was calculated using Eq. (7):

$$
\mathrm{IV}=\frac{(B-S) \times N \times 12.69}{W_{\mathrm{o}}}
$$

$\mathrm{IV}=$ iodine value of orange peel essential oil (mg $I_{2} /$ $100 \mathrm{mg}$ )

Determination of peroxide value of orange peel essential oil This was determined using the procedure described by Njoku and Evbuomwan (2014). Thirty milliliters of acetic acid chloroform solution was measured into a flask containing $2 \mathrm{~g}$ of the oil sample. A $0.5 \mathrm{ml}$ saturated solution of potassium iodide was then added, followed closely by the addition of $30 \mathrm{ml}$ of distilled water. The flask content was then titrated against $0.1 \mathrm{M}$ sodium thiosulfate until the yellow color almost disappeared; $0.5 \mathrm{ml}$ starch indicator was added and the titration continued until the end point (where the blue-black color just disappeared). A blank titration was equally performed. The peroxide value was calculated using Eq. (8):

$$
\mathrm{PV}=\frac{100 \times(B-S)}{W_{\mathrm{o}}}
$$

$\mathrm{PV}=$ peroxide value of orange peel essential oil $(\mathrm{mEq} \mathrm{O} / \mathrm{kg}$ )

Determination of refractive index of orange peel essential oil This was determined as reported by Adepoju and Eyibio (2016). A digital refractometer was used to determine the refractive index of the essential oil. Water at room temperature was circulated around the glass slide to keep the temperature uniform and also to normalize the refractometer. A syringe and needle were used to put few drops of oil into the glass slide of the refractometer, and the reading was recorded.

All experiments were carried out in triplicates, and average values taken.

\section{Characterization of orange peel dried pectin}

The dried pectin extracted from orange peels at the optimum processing conditions (the highest yield) was characterized by determining the physicochemical properties.
Determination of ash content of orange peel dried pectin This was determined as reported by Yadav et al. (2017). Five grams of the dried pectin sample was put into a weighed empty crucible. The crucible was transferred to a furnace set at $60{ }^{\circ} \mathrm{C}$ to burn off all the organic matter. The carbon charred and then burnt off as carbondioxide, leaving a dark ash. This process lasted for $24 \mathrm{~h}$. The crucible was taken out of the furnace and placed in a desiccator to cool. The crucible after cooling was reweighed again. The ash content was calculated using Eq. (9):

$$
\mathrm{AC}=\frac{W_{\mathrm{a}}}{W_{\mathrm{s}}} \times 100
$$

$\mathrm{AC}=$ ash content of orange peel dried pectin (\%), $W_{\mathrm{a}}=$ weight of ash $(\mathrm{g})$, and $W_{\mathrm{s}}=$ weight of sample $(\mathrm{g})$

\section{Determination of degree of esterification of orange peel dried pectin}

This was determined using the titrimetric method described by Silva et al. (2008). Twenty grams of dried pectin was moistened with ethanol and dissolved in $20 \mathrm{ml}$ of deionized water at $40{ }^{\circ} \mathrm{C}$. After complete dissolution of pectin, five drops of phenolphthalein were added to the solution. The solution was thereafter titrated with $0.5 \mathrm{M}$ sodium hydroxide, and the volume of the sodium hydroxide solution used for color change was recorded as $V_{1}$. Subsequently, $10 \mathrm{ml}$ of $0.5 \mathrm{M}$ sodium hydroxide was added, and the solution was shaken strongly and allowed to rest for $15 \mathrm{~min}$. Also, $10 \mathrm{ml}$ of $0.5 \mathrm{M}$ hydrochloric acid was added and the solution was shaken until the pink color disappeared. The solution was titrated with $0.5 \mathrm{M}$ sodium hydroxide for the last step, and the volume consumed was recorded as $V_{2}$. The degree of esterification was calculated using Eq. (10):

$$
\mathrm{DE}=\frac{V_{2}}{V_{1}+V_{2}} \times 100
$$

$\mathrm{DE}=$ degree of esterification of orange peel dried pectin $(\%), V_{1}=$ initial titer $(\mathrm{ml})$, and $V_{2}=$ final titer $(\mathrm{ml})$

\section{Determination of equivalent weight of orange peel dried pectin}

This was determined as reported by Yadav et al. (2017); $0.5 \mathrm{~g}$ of dried pectin was put in a $250 \mathrm{ml}$ conical flask, and $5 \mathrm{ml}$ ethanol was added. One gram of sodium chloride and $100 \mathrm{ml}$ of distilled water were added. Finally, six drops of phenol red was added and titrated against $0.1 \mathrm{M}$ sodium hydroxide. Titration point was indicated by pink color. The equivalent weight was calculated using Eq. (11): 


$$
\mathrm{EW}=\frac{W_{\mathrm{s}} \times 1000}{V_{\mathrm{a}} \times N_{\mathrm{a}}}
$$

$\mathrm{EW}=$ equivalent weight of orange peel dried pectin (\%), $V_{\mathrm{a}}=$ volume of alkali $(\mathrm{ml})$, and $N_{\mathrm{a}}=$ normality of alkali

\section{Determination of methoxyl content of orange peel dried pectin}

This was done using the Ranganna's method as reported by Yadav et al. (2017). The neutral solution was collected from determination of equivalent weight, and $25 \mathrm{ml}$ of sodium hydroxide was added. The mixed solution was stirred thoroughly and kept at room temperature for $30 \mathrm{~min}$. After $30 \mathrm{~min}, 25 \mathrm{ml}$ of $0.25 \mathrm{M}$ hydrochloric acid was added and titrated against $0.1 \mathrm{M}$ sodium hydroxide. The methoxyl content was calculated using Eq. (12):

$$
\mathrm{MTC}=\frac{V_{\mathrm{a}} \times N_{\mathrm{a}} \times 3.1}{W_{\mathrm{s}}}
$$

MTC = methoxyl content of orange peel dried pectin (\%)

\section{Determination of total anhydrouronic acid content of orange peel dried pectin}

This was done using the method adopted by Yadav et al. (2017). Total anhydrouronic acid content of dried pectin was obtained using Eq. (13):

$$
\mathrm{AUA}=\frac{176 \times 0.1 y \times 100}{W_{\mathrm{s}} \times 1000}+\frac{176 \times 0.1 z \times 100}{W_{\mathrm{s}} \times 1000}
$$

$\mathrm{AUA}=$ total anhydrouronic acid content of dried pectin (\%), $y=$ volume of $\mathrm{NaOH}$ from equivalent weight determination $(\mathrm{ml})$, and $z=$ volume of $\mathrm{NaOH}$ from methoxyl content determination $(\mathrm{ml})$

Determination of acetyl value of orange peel dried pectin This was done using the Ranganna's method as reported by Kliemann et al. (2009); $0.5 \mathrm{~g}$ of dried pectin sample was dissolved in $0.1 \mathrm{M}$ sodium hydroxide solution with stirring and allowed to stand overnight. The contents were diluted to $50 \mathrm{ml}$ with distilled water and an aliquot $(20 \mathrm{ml})$ was placed into the distillation apparatus. Magnesium sulfate-sulfuric acid solution $(20 \mathrm{ml})$ was also transferred to distillation apparatus and distilled, and about $100 \mathrm{ml}$ of distillate was collected. The distillate was titrated with $0.5 \mathrm{M}$ sodium hydroxide using phenol red indicator. A blank distillation using $20 \mathrm{ml}$ of the magnesium sulfate-sulfuric acid solution was carried out, and the distillate was titrated. The acetyl content was calculated using Eq. (14):

$$
\mathrm{ACV}=\frac{V_{\mathrm{a}} \times N_{\mathrm{a}} \times 4.3}{W_{\mathrm{s}}}
$$

$\mathrm{ACV}=$ acetyl value of orange peel dried pectin (\%)

\section{Response surface methodology (RSM)}

A Design Expert (version 6.0.6) software package was used for the experimental design, analyses, and model equation generation for the extraction parameters. Linear, two factorial interaction (2FI), quadratic, and cubic models were used in the analyses and were fitted to the experimental data. The results obtained were compared with the predicted values. Analysis of variance (ANOVA) was performed, and the $P$ value (probability of error value) was utilized in checking the significance of each regression coefficient. The optimal parameters were validated by repeating the experiment at the optimal conditions.

\section{Results and discussion}

Effects of processing factors on essential oil yield

The yield of essential oil ranged from 0.57-3.24\% (Table 1). This compares favorably with the findings of other researchers on essential oil yield from orange peels. Blanco et al. (1995) obtained maximum essential oil yield of $0.79 \%$ for Colombia orange peels using gas chromatography method. Ezejiofor et al. (2011) reported maximum essential oil yield of $0.6 \%$ using steam distillation method. Pultrini et al. (2006) achieved maximum essential oil yield of $0.5 \%$ using cold pressed extraction method. Sharma and Tripathi (2008) obtained maximum essential oil yield of $1.8 \%$ from Indian sweet orange Osbeck epicarp using hydro-distillation method. Hosni et al. (2010) published maximum essential oil yield of $1.89 \%$ from Tunisian citrus peels. Bustamante et al.

Table 1 Essential oil yield at various processing conditions

\begin{tabular}{llll}
\hline Run & Temperature $(C)$ & Time $(\mathrm{min})$ & EO yield(\%) \\
\hline 1 & 85.00 & 150.00 & 1.83 \\
2 & 100.00 & 180.00 & 2.26 \\
3 & 85.00 & 210.00 & 2.84 \\
4 & 95.00 & 210.00 & 3.24 \\
5 & 90.00 & 180.00 & 2.19 \\
6 & 90.00 & 180.00 & 2.04 \\
7 & 90.00 & 240.00 & 2.86 \\
8 & 90.00 & 120.00 & 0.57 \\
9 & 90.00 & 180.00 & 2.17 \\
10 & 90.00 & 180.00 & 2.08 \\
11 & 90.00 & 180.00 & 2.13 \\
12 & 80.00 & 180.00 & 0.62 \\
13 & 95.00 & 150.00 & 2.33 \\
\hline
\end{tabular}


(2016) obtained maximum essential oil yield of $2.3 \%$ for Valencia late orange peels using microwave-assisted hydro-distillation method. Giwa et al. (2018) achieved maximum essential oil yields of 4.40, 3.47, and 2.54\% using steam distillation, water distillation, and solvent extraction methods, respectively. Even though the results all fall within the range of 0.5 and $5.0 \%(w / v)$ as reported by Palazzolo et al. (2013), the differences could have been due to the nature of the fruits and extraction process vis-à-vis the processing conditions.

In Fig. 1, increase in extraction temperature and time leads to a corresponding increase in essential oil yield. However, at higher extraction temperatures and times, beyond the optimum, essential oil yield decreases. This agrees with the findings of Giwa et al. (2018) who also obtained an increasing trend while working on essential oil extraction from orange peels using water distillation method. At low temperatures, steam travels through the peels slowly and the pressure build up is not sufficient enough to extract the oil out of the peel matrix. However, as the temperature increases for a longer period of time, the oil will eventually break out of the peel matrix and thus be extracted. Nevertheless, extending the extraction duration at higher extraction temperatures caused substantial moisture loss leading to hardening of peels which consequently leads to a decrease in essential oil yield. This supports the findings of Kabuba (2009) while working on steam extraction of essential oils.

\section{Effects of processing factors on pectin yield}

The yield of pectin ranged from 12.93-29.05\% (Table 2). This compares favorably with the findings of other researchers on pectin yield from orange peels. El-Nawawi and Shehata (1987) and Marin et al. (2007) obtained pectin yield between $21-30$ and $13-23 \%$, respectively, while Hashmi et al. (2012), Kanmani et al. (2014), Dehankar et al. (2015), and Khan et al. (2015) reported maximum pectin yields of $20.12,29.41,20$, and $21 \%$, respectively. These differences could have been due to the nature of the fruits and extraction process vis-à-vis the processing conditions.

It was observed that increase in extraction time with extraction temperature leads to increase in pectin yield, with the maximum obtained at $95{ }^{\circ} \mathrm{C}$ and $105 \mathrm{~min}$, beyond which pectin yield levels off (Fig. 2). This agrees with the findings of Pagan et al. (2001), Mollea et al. (2008), and Gama et al. (2015) while working on pectin extraction from peach pomace, cocoa husks, and citric wastes, respectively. As temperature increases, the solubility of the extracted pectin increases which leads to increase extraction rate. However, beyond the optimum temperature, pectin yield decreases because of degradative action which results in pectin of lower molecular size not precipitable with alcohol. Also, it was observed that the longer the extraction duration, the higher the pectin yield. However, at longer durations beyond the optimum, the yield decreases. As the duration increases, the concentration of the pectin in the solution increases, leading to increase yield. However, beyond the optimum time at higher temperatures, thermal degradation occurs which leads to decrease pectin yield. This supports the findings of El-Nawawi and Shehata (1987), Kliemann et al. (2009), Tang et al. (2011), and Gama et al. (2015) while working on pectin extraction from orange, passion fruit, dragon fruit, and citric waste peels, respectively. Increase extraction temperature at low $\mathrm{pH}$ leads to corresponding increase in pectin yield (Fig. 3). Low pH signifies increase acid concentration (acidity), and

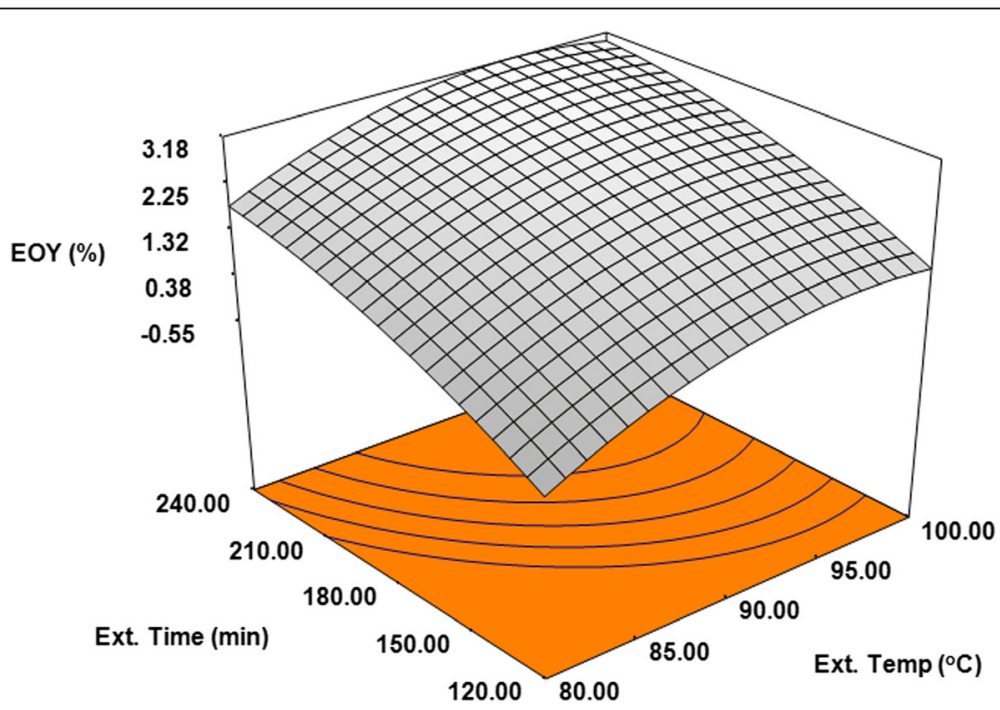

Fig. 1 Response surface plot of the effect of extraction temperature and extraction time on essential oil yield 
Table 2 Pectin yield at various processing conditions

\begin{tabular}{lllll}
\hline Run & Temperature $\left({ }^{\circ} \mathrm{C}\right)$ & Time $(\mathrm{min})$ & $\mathrm{pH}$ & Pectin yield $(\%)$ \\
\hline 1 & 90.00 & 90.00 & 2.00 & 19.12 \\
2 & 90.00 & 90.00 & 2.00 & 19.90 \\
3 & 95.00 & 105.00 & 1.50 & 29.05 \\
4 & 90.00 & 90.00 & 1.00 & 27.77 \\
5 & 85.00 & 75.00 & 2.50 & 14.53 \\
6 & 80.00 & 90.00 & 2.00 & 13.36 \\
7 & 90.00 & 90.00 & 2.00 & 18.83 \\
8 & 90.00 & 90.00 & 2.00 & 18.07 \\
9 & 90.00 & 90.00 & 2.00 & 18.69 \\
10 & 95.00 & 75.00 & 2.50 & 14.85 \\
11 & 85.00 & 75.00 & 1.50 & 15.70 \\
12 & 90.00 & 90.00 & 2.00 & 19.64 \\
13 & 90.00 & 60.00 & 2.00 & 13.55 \\
14 & 85.00 & 105.00 & 1.50 & 24.49 \\
15 & 90.00 & 90.00 & 3.00 & 12.93 \\
16 & 95.00 & 105.00 & 2.50 & 23.56 \\
17 & 85.00 & 105.00 & 2.50 & 22.51 \\
18 & 95.00 & 75.00 & 1.50 & 16.05 \\
19 & 100.00 & 90.00 & 2.00 & 26.83 \\
20 & 90.00 & 120.00 & 2.00 & 25.55 \\
\hline & & & &
\end{tabular}

according to Putnik et al. (2017), high acidity level increases extraction yields of various types of pectins and protopectins. This is due to the fractionation of glycosidic bonds in the neutral sugars because they are more sensitive to $\mathrm{pH}$ than the link between two galacturonic acids, leading to degradation of the neutral sugar side chains. Pagan and Ibarz (1999) and Pagan et al. (2001) while working on pectin extraction from fresh and stored peach pomace, respectively, observed that at constant extraction time, increase temperature with decrease $\mathrm{pH}$ increases pectin yield. The lowest yields of 12.93 and 13.36 were obtained at relatively high $\mathrm{pH}$ and low temperature levels, while the highest yields of 29.05 and 27.77 were obtained at relatively high temperature and low $\mathrm{pH}$ levels. It was observed that increasing the $\mathrm{pH}$ at relatively low temperature leads to drop in pectin yield. This is because high $\mathrm{pH}$ level leads to less degradation of the neutral sugar side chains, and at relatively low temperature, solubility of the extracted pectin decreases, hence decrease extraction rate with consequent low pectin yield. Similarly in Fig. 4, increase extraction time at low $\mathrm{pH}$ leads to corresponding increase in pectin yield. As observed earlier, low $\mathrm{pH}$ signifies increase acidity which increases extraction yields of various types of pectins and protopectins (Putnik et al., 2017). As the extraction proceeds, the pectin concentration in the solution increases. However, at higher durations, the extraction rate gradually decreases because the concentration gradient is reduced and the solution becomes more viscous (Coulson and Richardson 1978). This supports the observation of Maxwell et al. (2012) that increasing the acidity and extraction time increased pectin yield. Also, high concentration of hydrogen ions in the solvent activates the hydrolysis of protopectin at low $\mathrm{pH}$, causing repress of the ionization of the hydrated carboxylate groups by converting them into hydrated carboxylic acid groups (Sereewatthanawut et al. 2008 and Emaga et al. 2008). This loss of carboxylate groups decreases the repulsion of the polysaccharide molecules

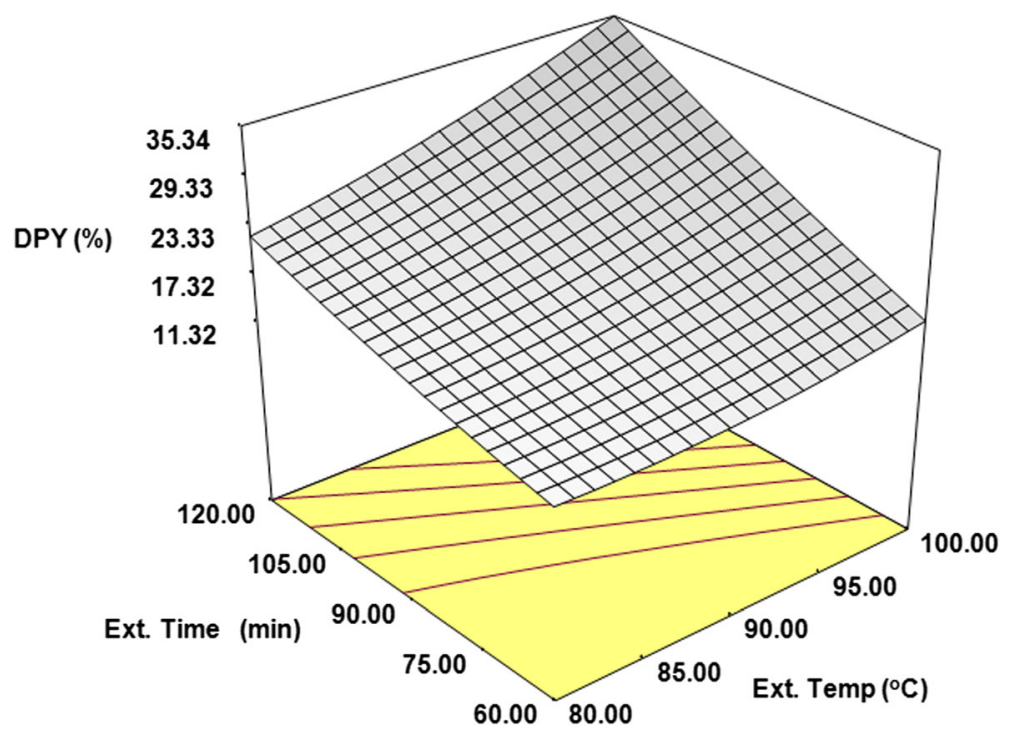

Fig. 2 Response surface plot of the effect of extraction temperature and extraction time on dried pectin yield 


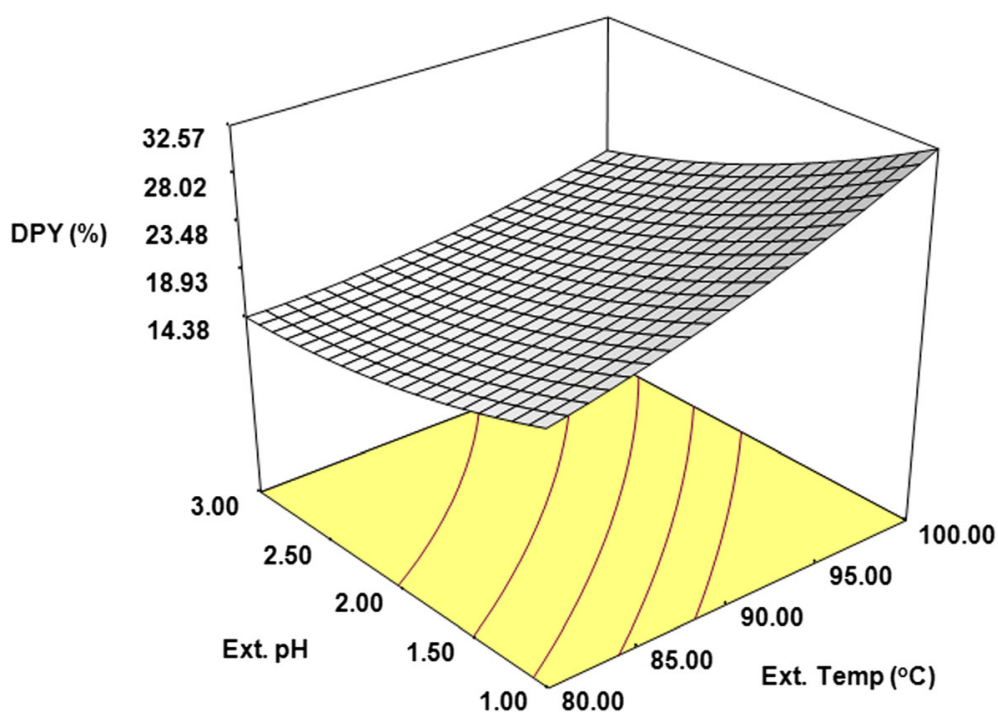

Fig. 3 Response surface plot of the effect of extraction temperature and extraction $\mathrm{pH}$ on dried pectin yield

which stimulates the gelation properties of pectin, thereby producing more precipitated pectin at lower $\mathrm{pH}$. As the duration extends, more pectin is produced up to the optimum, after which pectin yield levels off. This trend was established by Maxwell et al. (2012) while studying pectin as an emerging new bioactive food polysaccharide.

\section{Optimization of the oil and pectin extraction yields}

When selecting the appropriate model, several considerations were made which are selection of highest order polynomial where the additional terms are significant and there is no error in the model (model is not aliased), insignificant lack-of-fit, and the maximization of the "adjusted

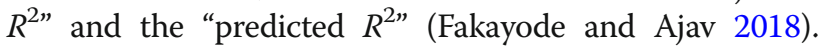

However, the cubic model is aliased, which implies that it cannot be selected. For the essential oil extraction, the linear model was suggested (Table 3). The final equation is given as Eq. (15):

$$
\text { Essential oil yield }\left(\% \frac{w}{v}\right)=-7.43+0.07 \mathrm{ET}+0.02 \mathrm{Et}
$$

$\mathrm{ET}=$ extraction temperature $\left({ }^{\circ} \mathrm{C}\right)$ and $E_{\mathrm{t}}=$ extraction time (min)

There is a direct relationship between the processing factors and essential oil yield as signified by the positive terms in the equation. Both processing factors influence

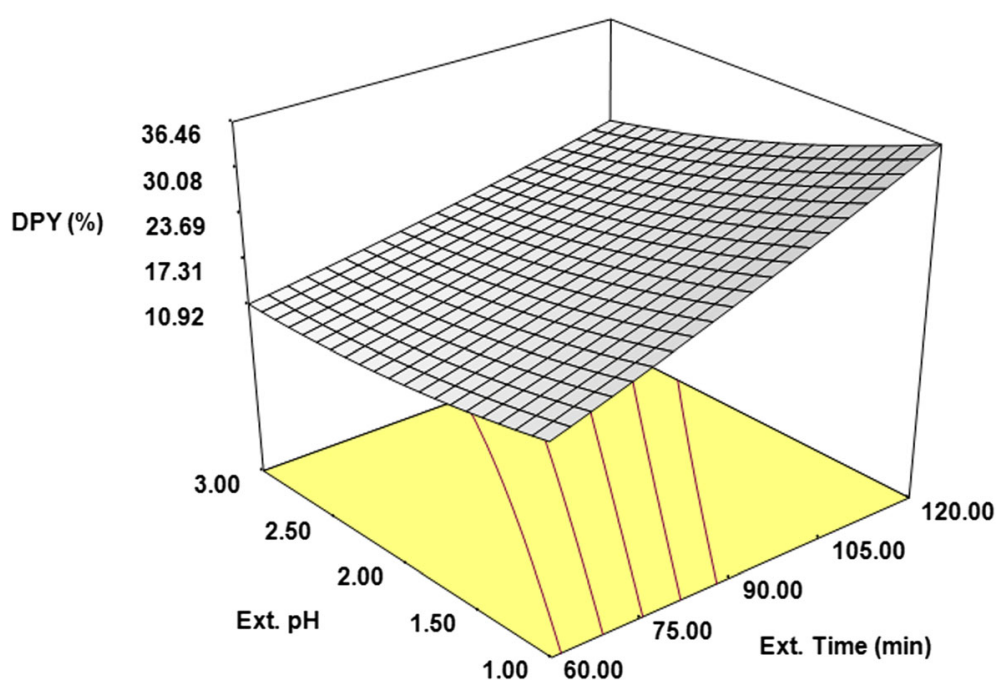

Fig. 4 Response surface plot of the effect of extraction time and extraction $\mathrm{pH}$ on dried pectin yield 
Table 3 Sequential model sum of squares and ANOVA for response surface linear model for essential oil extraction

\begin{tabular}{|c|c|c|c|c|c|c|}
\hline Source & Sum of squares & Df & Mean square & $F$ value & Prob $>F$ & \\
\hline Mean & 56.74 & 1 & 56.74 & - & - & \\
\hline Linear & 4.98 & 2 & 2.49 & 11.59 & 0.0025 & Suggested \\
\hline $2 \mathrm{Fl}$ & $2.500 \mathrm{E}-003$ & 1 & $2.500 \mathrm{E}-003$ & 0.01 & 0.9207 & \\
\hline Quadratic & 0.62 & 2 & 0.31 & 1.43 & 0.3006 & \\
\hline Cubic & 0.11 & 2 & 0.06 & 0.20 & 0.8229 & Aliased \\
\hline Residual & 1.41 & 5 & 0.28 & - & - & \\
\hline Total & 63.87 & 13 & 4.91 & - & - & \\
\hline Model & 4.98 & 2 & 2.49 & 11.59 & 0.0025 & \\
\hline A & 1.46 & 1 & 1.46 & 6.78 & 0.0263 & \\
\hline B & 3.52 & 1 & 3.52 & 16.40 & 0.0023 & \\
\hline Residual & 2.15 & 10 & 0.21 & - & - & \\
\hline Lack of fit & 2.13 & 6 & 0.36 & 91.80 & 0.0003 & \\
\hline Pure error & 0.015 & 4 & $3.870 \mathrm{E}-003$ & - & - & \\
\hline Correlation total & 7.12 & 12 & - & - & - & \\
\hline
\end{tabular}

Values $>0.05$ are not significant

$A$ represents extraction temperature, $B$ represents extraction time, $d f$ degree of freedom

essential oil yield (Table 4); however, it was observed that extraction temperature has higher influence on essential oil yield. This agrees with the observation of Giwa et al. (2018) which reported that extraction temperature was the most influential parameter affecting essential oil yield in their research work. The model $F$ value of 11.59 implies the model is significant. There is only a $0.25 \%$ chance that a "model $F$ value" this large could occur due to noise. Values of "Prob $>F$ " less than 0.0500 indicate model terms are significant. In this case, $A$ and $B$ (which represent extraction temperature and extraction time, respectively) are significant model terms. Values greater than 0.1000 indicate the model terms are not significant. If there are many insignificant model terms (not counting those required to support hierarchy), model reduction will be required for model improvement. However, this was not the case in the chosen model as both model terms are significant. The "lack of fit $F$ value" of 91.80 implies the lack of fit is significant. There is only a $0.03 \%$ chance that a "lack of fit $F$ value" this large could occur due to noise. The "Pred R-Squared" of 0.29 is not as close to the "Adj R-Squared" of 0.64 as might normally be expected. This may indicate a large block effect. "Adeq Precision" measures the signal-to-noise ratio and a ratio greater than 4 is desirable. "Adeq Precision" ratio of 9.73 indicates an adequate signal. This model can be used to navigate the design space. The model was significant with a very low probability value $(<0.0001)$ and a high coefficient of determination $\left(R^{2}=0.70\right)$. From Table 4 , it was observed that the 2FI model has the same $R^{2}$ value as the selected linear model, while the quadratic model (as the cubic model cannot be selected) has higher $R^{2}$ value compared to the linear model. However, the linear model has lower standard deviation value compared to the other two. Also, it was observed that for the three models, both

Table 4 Model selection for essential oil and pectin extraction

\begin{tabular}{lllllllll}
\hline Essential oil & \multicolumn{7}{c}{ Pectin } \\
\hline Model & Linear & 2FI & Quadratic & Cubic & Linear & 2FI & Quadratic & Cubic \\
Std. dev. & 0.46 & 0.49 & 0.47 & 0.53 & 2.25 & 2.37 & 2.62 & 0.67 \\
R $^{2}$ & 0.70 & 0.70 & 0.79 & 0.80 & 0.84 & 0.85 & 0.86 & 0.99 \\
Mean & 2.09 & 2.09 & 2.09 & 2.09 & 19.75 & 19.75 & 19.75 & 19.75 \\
Adjusted R & 0.64 & 0.60 & 0.63 & 0.53 & 0.80 & 0.78 & 0.73 & 0.98 \\
C.V. & 22.18 & 23.36 & 22.31 & 25.39 & 11.39 & 12.01 & 13.26 & 3.40 \\
Predicted R & 0.29 & 0.01 & -0.50 & -21.70 & 0.70 & 0.38 & -0.13 & 0.79 \\
PRESS & 5.05 & 7.12 & 10.67 & 161.73 & 146.73 & 304.36 & 557.50 & 102.72 \\
Adeq. Precision & 9.73 & 8.00 & 6.84 & 5.50 & 16.80 & 12.81 & 9.80 & 28.08 \\
Significant terms & $\mathrm{A}, \mathrm{B}$ & $\mathrm{A}, \mathrm{B}$ & $\mathrm{A}, \mathrm{B}$ & - & $\mathrm{A}, \mathrm{B}, \mathrm{C}$ & $\mathrm{A}, \mathrm{B}, \mathrm{C}$ & $\mathrm{A}, \mathrm{B}, \mathrm{C}$ & $\mathrm{B}, \mathrm{C}^{2}, \mathrm{AB}, \mathrm{BC}, \mathrm{A}^{3}, \mathrm{~B}^{3}, \mathrm{C}^{3}$ \\
\hline
\end{tabular}


model terms $A$ and $B$ are significant which shows absolute linearity (Table 4). The high coefficient of determination $\left(R^{2}=0.70\right)$ showed excellent correlations between the independent variables. This value indicates that the response model can explain $70 \%$ of the total variability in the responses.

For the pectin extraction, the linear model was suggested (Table 5). The final equation is given as Eq. (14):

Pectin yield (dry matter basis)

$$
=-31.17+0.42 \mathrm{ET}+0.26 \mathrm{Et}-4.94 \mathrm{pH}
$$

$\mathrm{ET}=$ extraction temperature $\left({ }^{\circ} \mathrm{C}\right), E_{\mathrm{t}}=$ extraction time (min), and $\mathrm{pH}=$ extraction $\mathrm{pH}$

There is a direct relationship between extraction temperature as well as extraction time and pectin yield as signified by the positive terms in the equation, while there is an inverse relationship between extraction $\mathrm{pH}$ and pectin yield. All the processing factors influence pectin yield (Table 4); however, it was observed that extraction $\mathrm{pH}$ has the highest influence on pectin yield. This was in line with the findings of Pinheiro et al. (2008), Kliemann et al. (2009), Kanmani et al. (2014), and Tiwari et al. (2017) which established that extraction $\mathrm{pH}$ was the most significant parameter that influences pectin yield in their research works. The model $F$ value of 27.05 implies the model is significant. There is only a $0.01 \%$ chance that a "model $F$ value" this large could occur due to noise. Values of "Prob $>F$ " less than 0.0500 indicate model terms are significant. In this case, $A, B$, and $C$ (which represent extraction temperature, time, and $\mathrm{pH}$, respectively) are significant model terms. Values greater than 0.1000 indicate the model terms are not significant. If there are many insignificant model terms (not counting those required to support hierarchy), model reduction may improve the selected model. However, this was not the case in the chosen model as all the model terms are significant. The "lack of fit $F$ value" of 16.17 implies the lack of fit is significant. There is only a $0.33 \%$ chance that a "lack of fit $F$ value" this large could occur due to noise. The "Pred R-Squared" of 0.70 is in reasonable agreement with the "Adj R-Squared" of 0.80 . "Adeq Precision" ratio of 16.80 obtained indicates an adequate signal. This implies that the model can be used to navigate the design space. The model was significant with a very low probability value $(<0.0001)$ and a high coefficient of determination $\left(R^{2}=0.84\right)$. From Table 4 , it was observed that both the 2FI and quadratic models (as the cubic model cannot be selected) have higher $R^{2}$ values compared to the linear model, but the latter has lower standard deviation value compared to the other two. Also, it was observed that for the three models, only the model terms $A, B$, and $C$ are significant, which also shows absolute linearity (Table 5 ). The high coefficient of determination $\left(R^{2}=0.84\right)$ showed excellent correlations between the independent variables. This value indicates that the response model can explain $84 \%$ of the total variability in the responses.

\section{Validation of selected models for essential oil and pectin extractions}

There was an excellent agreement between the observed and predicted values for the essential oil and pectin

Table 5 Sequential model sum of squares and ANOVA for response surface linear model for pectin extraction

\begin{tabular}{llllll}
\hline Source & Sum of squares & Df & Mean square & F value & Prob $>F$ \\
\hline Mean & 7800.46 & 1 & 7800.46 & - & - \\
Linear & 410.57 & 3 & 136.86 & 27.05 & $<0.0001$ \\
$2 \mathrm{FI}$ & 7.87 & 3 & 2.62 & 0.47 & 0.7107 \\
Quadratic & 4.50 & 3 & 1.50 & 0.22 & 0.8812 \\
Cubic & 65.90 & 4 & 16.47 & 36.63 & 0.0002 \\
Residual & 2.70 & 6 & 0.45 & - & - \\
Total & 8292.00 & 20 & 414.60 & - & - \\
Model & 410.57 & 3 & 136.86 & 27.05 & $<0.0001$ \\
A & 68.97 & 1 & 68.97 & 13.65 & 0.0020 \\
B & 243.98 & 1 & 243.98 & 48.21 & $<0.0001$ \\
C & 97.61 & 1 & 97.61 & 19.29 & 0.0005 \\
Residual & 80.97 & 16 & 5.06 & - & - \\
Lack of fit & 78.75 & 11 & 7.16 & 16.17 & $<0.0033$ \\
Pure error & 2.21 & 5 & 0.44 & - & - \\
Correlation total & 491.54 & 19 & - & - & - \\
\hline
\end{tabular}

Values $>0.05$ are not significant

$A$ represents extraction temperature, $B$ represents extraction time, $C$ represents extraction $\mathrm{pH}, d f$ degree of freedom 
extractions (Figs. 5 and 6). For the essential oil extraction, in the range of $80-100{ }^{\circ} \mathrm{C}$ for extraction temperature and $120-240 \mathrm{~min}$ for extraction time where the goal for essential oil yield was maximum, the predicted essential oil yield of $3.38 \%$ at extraction temperature of $95.23{ }^{\circ} \mathrm{C}$ and extraction time of $231.30 \mathrm{~min}$ was obtained with a desirability of 1.00 . Under these optimal conditions, the experimental value was $3.34 \%$. For the pectin extraction, in the range of $80-100{ }^{\circ} \mathrm{C}$ for extraction temperature, $60-120 \mathrm{~min}$ for extraction time, and 1.0-3.0 for extraction $\mathrm{pH}$ where the goal for pectin yield was maximum, RSM predicted pectin yield of $30.00 \%$ at extraction temperature of $93.07{ }^{\circ} \mathrm{C}$, extraction time of $117.00 \mathrm{~min}$, and extraction $\mathrm{pH}$ of 1.60 with a desirability of 1.00 . This was experimentally validated as $29.02 \%$. Deviations between experimental and predicted values were low and statistically insignificant for both extractions. This shows that the models chosen can adequately predict essential oil and pectin yields.

\section{Physicochemical properties of essential oil}

The physicochemical properties of essential oil are presented in Table 6 . The specific gravity of the essential oil was 0.84 . The specific gravity determines the weight of the essential oil. It is also important in determining the quality and purity of essential oil. Most of the essential oils have specific gravity ranging from 0.696-1.88 (Pedranti 2011). Specific gravity values of oils are less than 1 for most of the oils except few containing oxygenated aromatic compounds (Osagie et al. 1986). The extracted essential oil has a specific density less than 1 which implies that it is lighter than water and consequently will be insoluble in water.
The free fatty acid of the essential oil was $1.86 \mathrm{mg} \mathrm{KOH} /$ g. Rethinam (2003) reported that the maximum value for non-rancid acid is $5.00 \mathrm{mg} \mathrm{KOH} / \mathrm{g}$; hence, the extracted essential oil falls within the range of non-rancid acids. Fatty acid composition is a major determinant of oil quality. They are fatty acids which have broken away from oil molecules or triacylglycerols, and their presence indicates that degradation has occurred in the oil. Free fatty acids are less stable and are therefore very prone to oxidation, thereby producing rancidity. It is a key feature linked with the quality and commercial value of oils. The low free fatty acid obtained showed good oil quality.

The acid value of the essential oil was $3.71 \mathrm{mg} \mathrm{KOH} / \mathrm{g}$. Essential oils are concentrated and contain several volatile aroma compounds which are majorly free fatty acids. Free fatty acids are considered as degrading in oils because they are responsible for oil rancidity. Oils with low acidity are considered as neutralized and safe for making skin care products as high acidity of oils may be harmful for skin (Kumar 2014). The low acid value of the extracted essential oil indicates that the oil has excellent storage life.

The saponification value of the essential oil was $188 \mathrm{mg} \mathrm{KOH} / \mathrm{g}$. Saponification value is an indicator of the average molecular weight and hence chain length. It is inversely proportional to the molecular weight of the oil (Onwuka 2005). High saponification values of oils are due to the predominantly high proportion of shorter carbon chain lengths of fatty acids (Gohari et al. 2011). Low molecular weight (short to medium chain) fatty acids have more glyceride molecules per gram of fat than high molecular weight acids. Each glyceride molecule requires three $\mathrm{KOH}$ molecules for saponification; hence, the more the glyceride molecules, the greater the saponification value (Kirk and Sawyer 1991). Nagre et al. (2011)

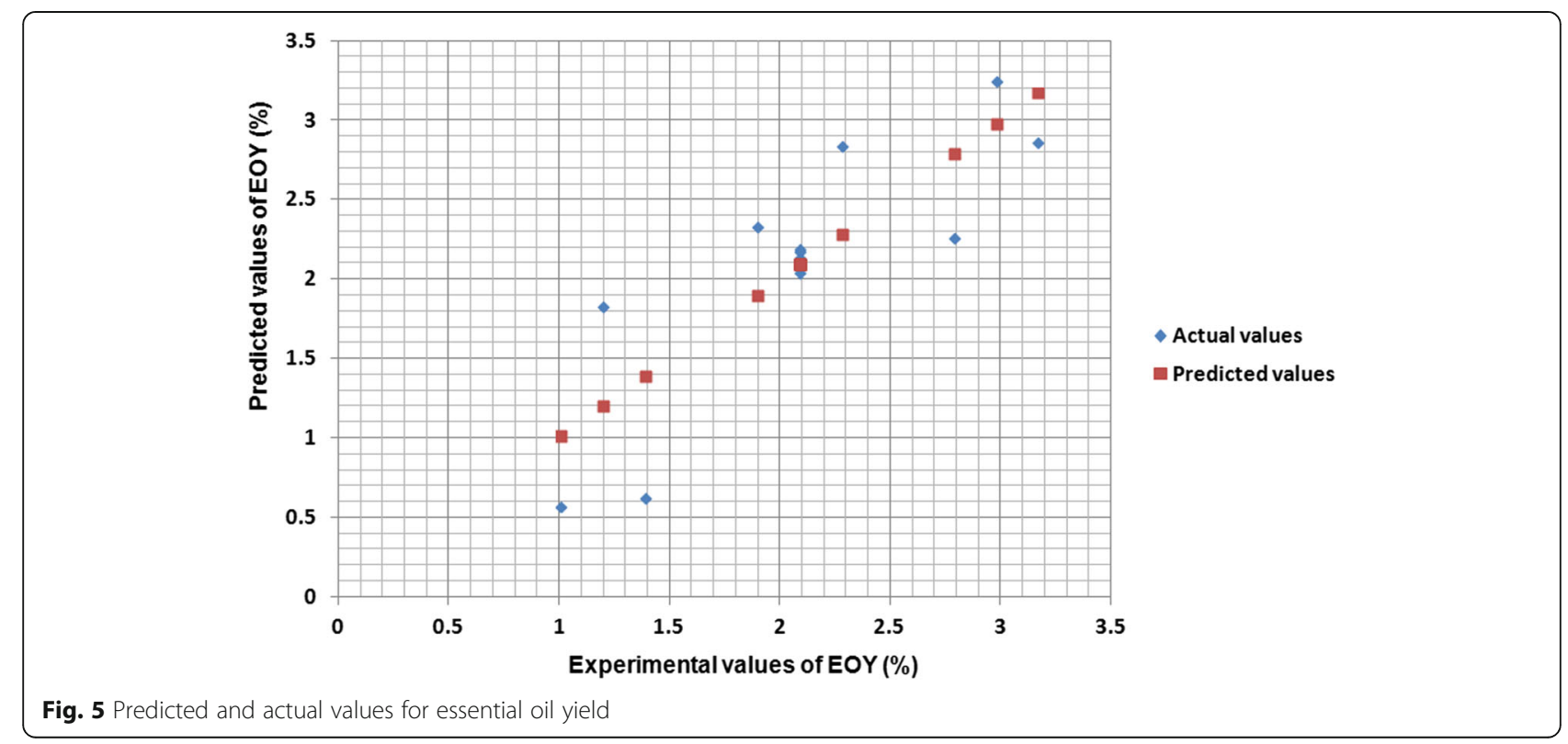




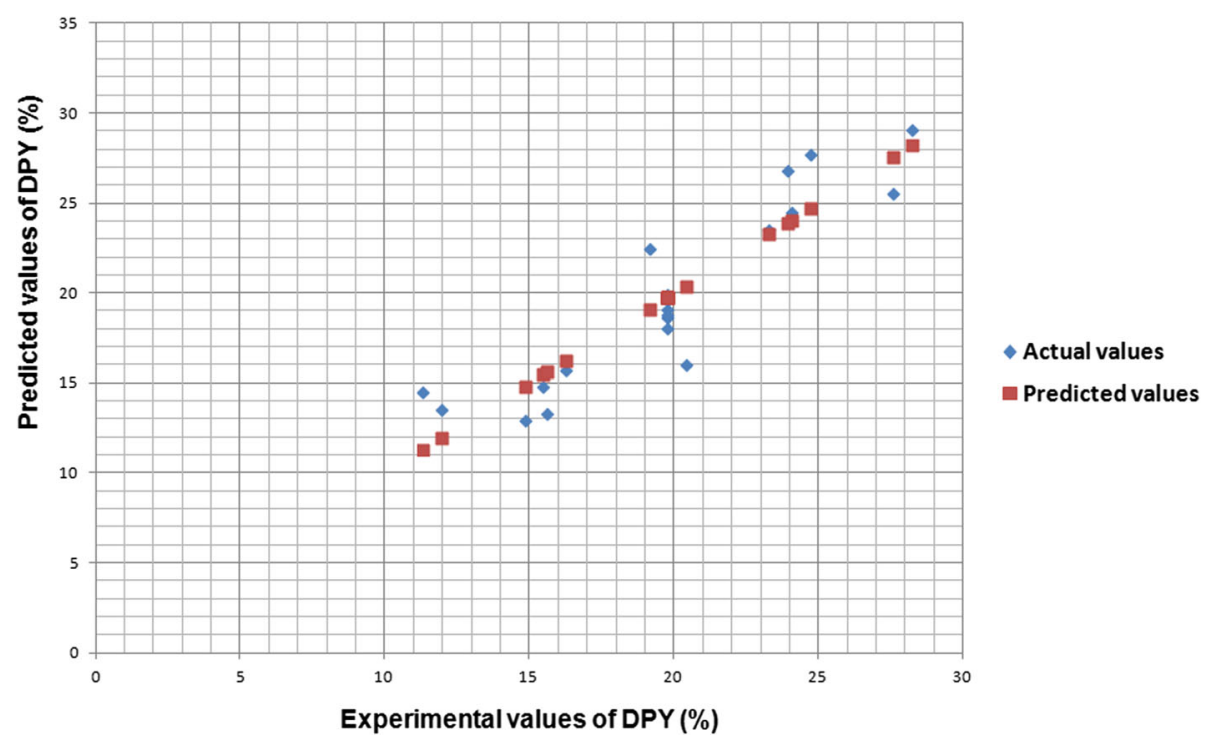

Fig. 6 Predicted and actual values for dried pectin yield

established that saponification value in combination with the acid value gives information on the quantity, type of glycerides, and mean weights of the acids in a given sample. Saponification value is of interest if the oil is for industrial purposes, as it has no nutritional significance (Dari 2009). The larger the saponification number, the better the soap making ability of the oil (Asiedu 1989).

The iodine value of the essential oil was $82 \mathrm{mg} I_{2} /$ $100 \mathrm{mg}$. The iodine value measures the degree of unsaturation in oil and could be used in quantifying the amount of double bonds present in the oil which reflects the susceptibility of oil to oxidation. It is useful in predicting the drying property of oils, and the moderate value obtained places the oil between non-drying and semi-drying oil; hence, the oil can be used in industries as feedstocks. Low iodine number implies the presence of few unsaturated bonds and hence low susceptibility to oxidative rancidity (Fox and Stachowiak 2007). Therefore, the lower the iodine value, the lower the degree of unsaturation and hence the lower the tendency of the oil to undergo oxidative rancidity.

Table 6 Physicochemical properties of essential oil

\begin{tabular}{ll}
\hline Parameters & Values \\
\hline Specific gravity $\left(\right.$ at $\left.20^{\circ} \mathrm{C}\right)$ ) & 0.84 \\
Free fatty acid & $1.86 \mathrm{mg} \mathrm{KOH} / \mathrm{g}$ \\
Acid value & $3.71 \mathrm{mg} \mathrm{KOH} / \mathrm{g}$ \\
Saponification value & $188 \mathrm{mg} \mathrm{KOH} / \mathrm{g}$ \\
lodine value & $82 \mathrm{mg} \mathrm{I} / 100 \mathrm{mg}$ \\
Peroxide value & $16 \mathrm{mEq} \mathrm{O} / 2 / \mathrm{kg}$ \\
Refractive index (at $\left.20^{\circ} \mathrm{C}\right)$ & 1.47 \\
\hline
\end{tabular}

The peroxide value of the essential oil was $16 \mathrm{mEq} \mathrm{O}_{2} / \mathrm{kg}$. Peroxide value gives a measure of the extent to which the oil has undergone primary oxidation. Detection of peroxide shows an initial evidence of rancidity in unsaturated fats and oils. The double bonds found in essential oils play a role in autoxidation (a free radical reaction involving oxygen that leads to deterioration of oils which form off-flavors and off-odors.). Oils with a high degree of unsaturation are most susceptible to autoxidation, and peroxides are intermediates in the autoxidation reaction. Peroxide value is useful for assessing the extent to which spoilage has advanced. The low peroxide value obtained from the extracted essential oil means that the oil will be more stable, and if stored properly, the shelf life will be extended. The International Olive Council (IOC) standard is $<20 \mathrm{mEq} \mathrm{O}_{2} / \mathrm{kg}$ oil (Mailer and Beckingham 2006). In general, peroxide levels higher than $20 \mathrm{mEq} \mathrm{O}_{2} / \mathrm{kg}$ lead to less stable oil with a shorter shelf life (Mailer and Beckingham 2006). Therefore, the peroxide value obtained from the extracted essential oil shows that the oil is stable.

The refractive index of the essential oil was 1.47. It measures the refraction of light rays as these pass through the oil. The refractive index is a unique number that designates how the oil responds to and bends light. Essentially, it tests how the speed of light is altered when passing through the oil. Kumar (2014) categorized a refractive index of 1.47 as highly pure. Therefore, the refractive index obtained from the extracted essential oil shows that the oil is highly pure. One point worthy of note however is that the refractive index is only a qualitative test of purity of essential oils and does not give percentage purity. 


\section{Physicochemical properties of dried pectin}

The physicochemical properties of dried pectin are presented in Table 6.

The degree of esterification (DE) of the dried pectin was $60.4 \%$. The degree of esterification is an important molecular index for pectin classification that describes the extent to which carboxyl groups in pectin molecules exist as the methyl ester. The pectin obtained can be categorized as high methoxyl pectin (HMP) because it has a high percentage of degree of esterification greater than $50 \%$. A high degree of esterification allows pectin to form gel quickly at high temperatures, having a more effective action on the lipid profile (Brouns et al. 2012; Dominiak et al. 2014). However, the degree of esterification represents only the ratio between methanol-esterified carboxyl groups and free carboxyl groups, whereas the methoxyl rate refers to the amount of methoxyl groups in a sample (Gnanasambandam and Proctor 1999). Therefore, the degree of esterification should not be assessed separately, as it does not represent the actual amount of methyl esterifications, especially when the galacturonic acid content is low. High methoxyl pectins (HMP) (with DE > 50\%) require a relatively high concentration of soluble solids and a low $\mathrm{pH}$ for gel formation, while low methoxyl pectins (LMP) (with $\mathrm{DE}<50 \%$ ) form rigid gels by the action of calcium or multivalent cations, which cross-link the galacturonic acid chains (Garna et al. 2004).

The equivalent weight was 599.74. Equivalent weight is a salient physical property of pectin. It is the most important characteristic in determining the functional behavior of pectin. Gelling abilities of individual pectin are tied very closely with equivalent weight. High equivalent weight has higher gel forming effect. Low equivalent weight means higher partial degradation of the pectin which is disadvantageous (Yandav et al. 2017).

The methoxyl content of the dried pectin was $6.23 \%$. Kanmani et al. (2014) established that the methoxyl content of pectin usually varies from $0.2-12 \%$ depending on the source and method of extraction. Since the value obtained was below 7\%, the dried pectin is of low ester characteristic, which implies that it is desirable in terms of quality. Pectins with low methoxyl content will form a thermo-irreversible gel, which means that it will stay gelled even when heated to temperatures that would normally melt it (Yapo and Koffi 2014). They are used in the food industry to make low-sugar jams because it does not require high-sugar levels to gel and is being utilized for pastries and molecular recipes designed not to be very sweet. They are used as a gelling agent, thickening agent, and stabilizer and can also be used as a fat substitute in baked goods and to stabilize acidic protein drinks such as drinking yogurt (Tiwari et al. 2017).

The total anhydrouronic acid content of the dried pectin was $70.9 \%$ which indicates its purity. According to the Food Chemical Codex (FCC), Food and Agriculture Organization (FAO), and European Union (EU), pectin must consist of at least $65 \%$ of galacturonic acid (Willats et al. 2006). Anhydrouronic acid content is important to the gelling capabilities of a given pectin. The high value obtained means that the extracted pectin has a low amount of protein.

The acetyl value of the dried pectin was $0.4 \%$. Ranganna (2002) reported that the gelling capacity of pectin decreased with increase in the degree of acetylation. If acetyl group is present in pectin, it inhibits gel formation. The low value obtained makes the pectin to be a good gelling agent.

\section{Conclusions}

The effects of processing parameters on essential oil and pectin extractions from orange peels have been established. Essential oil and pectin yields ranged from $0.57-3.24 \%$ and $12.93-29.05 \%$, respectively. The predicted optimum value for essential oil yield was $3.38 \%$ at extraction temperature of $95.23{ }^{\circ} \mathrm{C}$ and extraction time of $231.30 \mathrm{~min}$, while the predicted optimum value for pectin yield was $30.00 \%$ at extraction temperature of $93.07{ }^{\circ} \mathrm{C}$, extraction time of $117.00 \mathrm{~min}$, and extraction $\mathrm{pH}$ of 1.60 . Deviations between experimental and predicted values were low and statistically insignificant. All processing factors have significant effects on both extractions. The models adequately predicted the extraction processes. The suitability of essential oil and pectin for different purposes is determined by their physicochemical properties which is highly important. The physicochemical properties of the essential oil and pectin extracted at the optimum conditions fell within tolerable and acceptable range.

\section{Abbreviations}

AC: Ash content of orange peel dried pectin (\%); ACV: Acetyl value of orange peel dried pectin (\%); AUA: Total anhydrouronic acid content of dried pectin (\%); AV: Acid value of orange peel essential oil (mg KOH/g); B: Blank titration value $(\mathrm{ml})$; DE: Degree of esterification of orange peel dried pectin (\%); DPY: Dried pectin yield (\%); EOY: Essential oil yield (\%); ET: Extraction temperature $\left({ }^{\circ} \mathrm{C}\right) ; E_{\mathrm{t}}$ : Extraction time $(\mathrm{min})$; EW: Equivalent weight of orange peel dried pectin (\%); FFA: Free fatty acid of orange peel essential oil (mg KOH/g); IV: lodine value of orange peel essential oil ( $\mathrm{mg} \mathrm{/2} / 100 \mathrm{mg}$ ); MTC: Methoxyl content of orange peel dried pectin (\%); N: Normality of the ethanolic potassium hydroxide $(0.1 \mathrm{M})$; $\mathrm{pH}$ : Extraction $\mathrm{pH}$; PV: Peroxide value of orange peel essential oil $\left(\mathrm{mEq} \mathrm{O}_{2} / \mathrm{kg}\right)$; $S$ : Sample titration value $(\mathrm{ml})$; SG: Specific gravity of orange peel essential oil; SV: Saponification value of orange peel essential oil (mg KOH/g); $V$ : Volume of $0.1 \mathrm{M}$ potassium hydroxide used $(\mathrm{ml}) ; V_{1}$ : Initial titer $(\mathrm{ml}) ; V_{2}$ : Final titer $(\mathrm{ml}) ; W_{\mathrm{a}}$ : Weight of ash (g); $W_{\mathrm{b}}$ : Weight of specific gravity bottle filled with oil $(\mathrm{g}) ; W_{\mathrm{d}}$ : Weight of dried pectin obtained $(\mathrm{g}) ; W_{\mathrm{e}}$ : Weight of empty flask $(\mathrm{g}) ; W_{\mathrm{f}}$ : Weight of flask and extracted oil $(g) ; W_{\circ}$ : Weight of oil $(g) ; W_{p}$ : Initial weight of orange peel powder used for ex traction $(g) ; W_{s}$ : Weight of sample $(g) ; W_{w}$ : Weight of specific gravity bottle filled with water (g); $y$ : Volume of $\mathrm{NaOH}$ from equivalent weight determination $(\mathrm{ml})$; $z$ : Volume of $\mathrm{NaOH}$ from methoxyl content determination (ml)

\section{Acknowledgements}

Authors would like to appreciate the Department of Agricultural and Food Engineering, University of Uyo, Akwa Ibom State, Nigeria, for providing the facilities to carry out the research work. 


\section{Availability of data and materials}

Research data have been provided in the manuscript.

\section{Authors' contributions}

OAF designed the work, analyzed the results, and wrote the paper. KEA carried out the experiments. Both authors read and agreed with the final manuscript preparation.

\section{Authors' information}

OAF is a senior lecturer in Agricultural and Food Engineering, Faculty of Engineering, University of Uyo, Uyo, Akwa Ibom State, Nigeria. He is a registered engineer with the Council for the Regulation of Engineering in Nigeria (COREN) and a member of several professional bodies which include The American Society of Agricultural and Biological Engineers (ASABE), The Nigerian Society of Engineers (NSE), The Nigerian Institution of Agricultural Engineers (NIAE), and The Nigerian Institute of Food Science and Technology (NIFST). He teaches and supervises students at both the undergraduate and postgraduate levels.

KEA is a graduate of Food Engineering, Faculty of Engineering, University of Uyo, Uyo, Akwa Ibom State, Nigeria.

\section{Ethics approval and consent to participate}

Not applicable

\section{Consent for publication}

Not applicable

\section{Competing interests}

The authors declare that they have no competing interests.

\section{Publisher's Note}

Springer Nature remains neutral with regard to jurisdictional claims in published maps and institutional affiliations.

Received: 18 May 2018 Accepted: 7 September 2018

Published online: 23 September 2018

\section{References}

Adepoju TF, Eyibio U. Comparative study of response surface methodology (RSM) and artificial neural network (ANN) on oil extraction from Citrus sinensis oilseed and its quality characterization. Chem Res J. 2016;1(5):37-50.

Asiedu JJ. Processing tropical crops. A technological approach. London: Macmillan Publishers; 1989. p. 170-2. 226-246

Bakkali F, Averbeck S, Averbeck D, Idaomar M. Biological effects of essential oils - a review. Food Chem Toxicol. 2008;46:446-75.

Blanco TC, Stashenko EE, Combariza MY, Martinez JR. Comparative study of Colombian citrus oils by high-resolution gas chromatography and gas chromatography-mass spectrometry. J Chromat A. 1995:697:501-13.

Braddock RJ, Temelli F, Cadwallader KR. Citrus essential oils - a dossier for material safety data sheets. Food Tech. 1986;40(11):114-6.

Brouns F, Theuwissen E, Adam A, Bell M, Berger A, Mensink RP. Cholesterollowering properties of different pectin types in mildly hyper-cholesterolemic men and women. Eur J Clin Nutr. 2012;66:591-9.

Burt S. Essential oils: their antibacterial properties and potential applications in foods - a review. Int J Food Microbiol. 2004:94:223-53.

Bustamante J, van Stempvoort S, García-Gallarreta M, Houghton JA, Briers HK, Budarin VL, Matharu AS, Clark JH. Microwave assisted hydro-distillation of essential oils from wet citrus peel waste. J Clean Prod. 2016;137:598-605.

Chanthaphon A, Chanthachum S, Hongpattarakere T. Antimicrobial activities of essential oils and crude extracts from tropical citrus spp. against food-related microorganisms. J Sci Tech. 2008:30(1):125-31.

Coulson JM, Richardson JF. Chemical engineering, Vol. II. New York: Pergamon Press; 1978. p. 375.

Dari L. Effect of different solvents on the extraction of soya bean oil. Ghana: Dissertation, Kwame Nkrumah University of Science and Technology; 2009.

Dehankar PB, Patil NS, Mane P, Mane J. Recycling of orange peels as pectin - a valuable product. Int J Inf and Fut Res. 2015;2(9):3041-8.

Dominiak M, Søndergaard KM, Wichmann J, Vidal-Melgosa S, Willats WGT, Meyer AS, Mikkelsen JD. Application of enzymes for efficient extraction, modification, and development of functional properties of lime pectin. Food Hydrocol. 2014;40:273-82.
Dugo P, Mondello L, Dugo L, Stancanelli R, Dugo G. LC-MS for the identification of oxygen heterocyclic compounds in citrus essential oils. J Pharmacol Biomed Anal. 2000;24(1):147-54.

El-Nawawi SA, Shehata FR. Extraction of pectin from Egyptian orange peel. Factors affecting the extraction. Biol Wastes. 1987;20:281-90.

Emaga TH, Ronkart SN, Robert C, Wathelet B, Paquot M. Characterisation of pectins extracted from banana peels (Musa AAA) under different conditions using an experimental design. Food Chem. 2008;108(2):463-71.

Ezejiofor TIN, Eke NV, Okechukwu RI, Nwoguikpe RN, Duru CM. Waste to wealth: industrial raw materials potential of peels of Nigerian sweet orange (Citrus sinensis). Afr J Biotech. 2011;10(33):6257-64.

Fakayode OA, Ajav EA. Process optimization of mechanical oil expression from moringa (Moringa oleifera) seeds. Ind Crop Prod. 2016;90:142-51.

Fakayode OA, Ajav EA (2018) Development, testing and optimization of a screw press oil expeller for moringa (Moringa oleifera) seeds. Agric res, doi:org/ https://doi.org/10.1007/s40003-018-0342-6.

Fakayode OA, Ajav EA, Akinoso R. Effects of processing factors on the quality of mechanically expressed moringa (Moringa oleifera) oil: a response surface approach. J of Food Proc Eng. 2016;40(4):1-12.

Fan X, Wang X, Chen F. Biodiesel production from crude cottonseed oil: an optimization process using response surface methodology. The Open Fuels and Ener Sci J. 2011:4:1-8.

Fernández-Lopes JM, Fernandez-Ginés L, Aleson-Carbonel E, Sendra E, Sayas-Barberá JA, Pérez-Alves A. Application of functional citrus byproducts to meat products. Trends Food Sci Tech. 2004;15:176-85.

Fox NJ, Stachowiak GW. Vegetable oil-based lubricant - a review of oxidation. Tribol Int. 2007:40(7):1035-46.

Gama B, De Farias Silva CE, Oliveira Da Silva LM, Abud AKS. Extraction and characterization of pectin from citric waste. Chem Eng Trans. 2015;44:259-64.

Garna H, Mabon N, Wathelet B, Paquot M. New method for a two-step hydrolysis and chromatographic analysis of pectin neutral sugar chains. J Agric Food Chem. 2004:52:4652-9.

Giwa SO, Muhammad M, Giwa A. Utilizing orange peels for essential oil production. J Eng App Sci. 2018;13(1):17-27.

Gnanasambandam R, Proctor A. Preparation of soy hull pectin. Food Chem. 1999; 65:461-7.

Gohari AA, Farhoosh R, Haddad KMK. Chemical composition and physicochemical properties of pumpkin seeds (Cucurbita pepo var. styriaka) grown in. Iran J Agric Sci Tech. 2011;13:1053-63.

Hashmi SH, Ghatge P, Machewad GM, Pawar S. Studies on extraction of essential oil and pectin from sweet orange. J Food Proc Tech. 2012;1(5):1-3.

Hosni K, Zahed N, Chrif R, Abid I, Medfei W, Kallel M, Ben Brahim N, Sebei H. Composition of peel essential oils from four selected Tunisian citrus species: evidence for the genotypic influence. Food Chem. 2010;123: 1098-104.

Kabuba JT. Steam extraction of essential oil: investigation of process parameters. South Africa: Dissertation, University of Johannesburg; 2009.

Kanmani P, Dhivya E, Aravind J, Kumaresan K. Extraction and analysis of pectin from citrus peels: augmenting the yield from citrus limon using statistical experimental design. Iranica J Energy Env. 2014;5(3):303-12.

Khan M, Bibi N, Zeb A. Optimization of process conditions for pectin extraction from citrus peel. Sci Tech Dev. 2015;34(1):9-15.

Kirk RS, Sawyer R. Pearson's composition and analysis of foods. 9th ed. Harlow: AWL; 1991.

Kliemann E, de Simas KN, Amante ER, Prudencio ES, Teofilo RF, Ferreira MMC, Amboni RD. Optimisation of pectin acid extraction from passion fruit peel (Passiflora edulis flavicarpa) using response surface methodology. Int J Food Sci Tech. 2009:44:476-83.

Kumar A. Physico-chemical and natural products investigations of essential oil from the rhizomes of Kaempferia galanga L. Der Chem Sinica. 2014;5(2):91-4.

Mailer R, Beckingham C (2006) Testing olive oil quality: chemical and sensory methods. Primefact Bulletin.

Marin FR, Soler-Rivas C, Benavente-Garcia O, Castillo J, Perez-Alvarez JA. By-products from different citrus processes as a source of customized functional fibres. Food Chem. 2007;100:736-41.

Maxwell EG, Belshaw NJ, Waldron KW, Morris VJ. Pectin - an emerging new bioactive food polysaccharide. Trends Food Sci Tech. 2012;24:64-73.

May CD. Industrial pectins: sources, production and applications. Carbohyd Polym. 1990;12:79-99.

Mollea C, Chiampo F. Conti R. Extraction and characterization of pectins from cocoa husks: a preliminary study. Food Chem. 2008;107:1353-6. 
Nagre RD, Oduro I, Ellis WO. Comparative physico-chemical evaluation of kombo kernel fat produced by three different processes. Afr J Food Sci Tecn. 2011; 2(4):83-91.

Njoku VI, Evbuomwan BO. Analysis and comparative study of essential oil extracted from Nigerian orange, lemon and lime peels. Greener J Chem Sci Tech. 2014;1(1):6-14.

Nogueira LAH, Lora EES, Trossero MA, Frisk T. Dendroenergia: fundamentos e aplicações. Rio de Janeiro: Interciência; 2000. p. 199.

Onwuka Gl. Food analysis and instrumentation: theory and practice. 1st ed. Lagos: Naphthali Prints; 2005. p. 219.

Osagie AU, Okoye WI, Oluwayose BO, Dawodu DA. Chemical quality parameters and fatty acid composition of oils of some underexploited tropical seeds. Nig J Appl Sci. 1986;4(2):151-62.

Pagan J, Ibarz A. Extraction and rheological properties of pectin from fresh peach pomace. J Food Eng. 1999;39:193-201.

Pagan J, Ibarz A, Llorca M, Pagan A, Barbosa-Canovas GV. Extraction and characterization of pectin from stored peach pomace. Food Res Int. 2001;34: 605-12.

Palazzolo E, Laudicina VA, Germanà MA. Current and potential use of citrus essential oils. Current Org Chem. 2013;17:3042-9.

Pandharipande S, Makode H. Separation of oil and pectin from orange peel and study of effect of $\mathrm{pH}$ of extracting medium on the yield of pectin. J Eng Res Stud. 2012:3(2):6-9.

Pedranti J (2011). Physicochemical testing of essential oils - part 1 - specific gravity test. Jo's Health Corner Bulletin Available online at http:// joshealthcorner.blogspot.com/2011/07/physicochemical-testing-of essential. html. Assessed 30/08/2018.

Pinheiro ES, Silva IM, Gonzaga LV, Amante ER, Teofilo RF, Ferreira MM, Amboni RD. Optimization of extraction of high-ester pectin from passion fruit. Bioresour Technol. 2008;99:5561-6.

Pultrini AM, Galindo LA, Costa M. Effects of the essential oil from Citrus aurantium in experimental anxiety models in mice. J Life Sci. 2006;78:1720-5.

Putnik P, Kovacevic DB, Jambrak AR, Barba FJ, Cravotto G, Binello A, Lorenzo JM, Shpigelman A. Innovative "green" and novel strategies for the extraction of bioactive added value compounds from citrus wastes - a review. Molecules. 2017;22:1-24

Ranganna S. Pectin: handbook of analysis and quality control for fruit and vegetable products. USA: Tata McGraw-Hill Publishing Company Ltd; 2002. p. 31-47.

Rehmann ZU, Salatiya AM, Shah WH. Utilization of mango peels as a source of pectin. J Chem Soc of Pak. 2004;26:73-6.

Rethinam P. New approaches to coconut, oils and fats. Afri J Food Agric Nutr Dev. 2003;19(2):22-5.

Rossi D, Guerrini A, Maietti S, Bruni R, Paganetto G, Poli F, Scalvenzi RM, Saro K, Sacchetti G. Chemical fingerprinting and bioactivity of Amazonian Ecuador croton lechleri Müll. Arg. (Euphorbiaceae) stem bark essential oil: a new functional food ingredient? Food Chem. 2011;126:837-48.

Rouse AH, Crandall PC. Nitric acid extraction of pectin from citrus peel. Proc Fla State Hort Soc. 1976;89:166-76.

Sereewatthanawut I, Prapintip S, Watchiraruji K, Goto M, Sasaki M, Shotipruk A. Extraction of protein and amino acids from deoiled rice bran by subcritical water hydrolysis. Bioresour Technol. 2008;99(3):555-61.

Sharma N, Tripathi A. Effects of Citrus sinensis (L.) Osbeck epicarp essential oil on growth and morphogenesis of Aspergillus niger (L.) Van Tieghem. Microbiol Res. 2008;163:337-44.

Takeoka GR, Gerhard HF, Dao LT. Effect of heating on the characteristics and chemical composition of selected frying oils and fats. J Agric Food Chem. 1997:45:3244-9.

Tang PY, Wong CJ, Woo KK. Optimization of pectin extraction from peel of dragon fruit (Hylocereus polrhizus). Asian J Bio Sci. 2011:1-7.

The Daily Records (2018) Top 10 largest citrus producing countries in the world. The Daily Records Bulletin http://www.thedailyrecords.com/2018-2019-2020 2021/world-famous-top-10-list/world/largest-citrus-producing-countriesworld-statistics-states/6867/. Assessed 18/08/2018.

Thormar H. Lipids and essential oils as antimicrobial agents. Chichester: Wiley Publishers; 2011.

Tiwari AK, Saha SN, Yadav VP, Uadhyay UK, Katiyar D, Mishra T. Extraction and characterization of pectin from orange peels. Int J Biotech Biochem. 2017;13: $39-47$.

USDA (2018) Citrus: world markets and trade. United States Department of Agriculture, Foreign Agricultural Service 2018
Willats WGT, Knox JP, Mikkelsen JD. Pectin: new insights into an old polymer are starting to gel. Trends in Food Sci Tech. 2006;17:97-104.

Yadav SD, Bankar NS, Waghmare, NN, Shete DC (2017) Extraction and characterization of pectin from sweet lime. 4th International Conference on Multidisciplinary Research \& Practice, pp. 58-63.

Yapo BM, Koffi KL. Extraction and characterization of highly gelling low methoxy pectin from cashew apple pomace. Foods. 2014;3:1-12.

Yu JQ, Lei JC, Zhang XQ, Yu HD, Tian DZ, Liao ZX, Zou GL. Anticancer, antioxidant and antimicrobial activities of the essential oil of Lycopus lucidus Turcz. var. hirtus Regel. Food Chem. 2011;126:1593-8.

Zoubiri S, Baaliouamer A. Potentiality of plants as source of insecticide principles. J Saudi Chem Soc. 2014;18:925-38.

\section{Submit your manuscript to a SpringerOpen ${ }^{\circ}$ journal and benefit from:}

- Convenient online submission

- Rigorous peer review

- Open access: articles freely available online

- High visibility within the field

- Retaining the copyright to your article

Submit your next manuscript at $\boldsymbol{\nabla}$ springeropen.com 